\title{
Reiterated homogenization of monotone operators
}

\author{
Jacques-Louis LIONS ${ }^{a}$, Dag LUKKASSEN ${ }^{\mathrm{b}}$, Lars-Erik PERSSON ${ }^{\mathrm{c}}$, \\ Peter WALL ${ }^{\mathrm{c}}$ \\ a Collège de France, 3, rue d'Ulm, 75231 Paris cedex 05, France \\ ${ }^{b}$ Department of Mathematics, HiN, Narvik Institute of Technology, N-8505 Narvik, Norway \\ and Norut Technology Ltd., N-8500 Narvik, Norway \\ ${ }^{c}$ Department of Mathematics, Luleå University of Technology, S-971 87 Luleå, Sweden
}

(Reçu et accepté le 15 février 2000)

\begin{abstract}
In this Note we study reiterated homogenization of nonlinear equations of the form $-\operatorname{div}\left(a\left(x / \varepsilon, x / \varepsilon^{2}, \mathrm{D} u_{\varepsilon}\right)\right)=f$, where $a$ is periodic in the first two arguments and monotone in the third. We state that $u_{\varepsilon}$ converges weakly in $\mathrm{W}^{1, p}(\Omega)$ (and even in some multiscale sense), as $\varepsilon \rightarrow 0$, to the solution $u_{0}$ of a limit problem. Moreover, we give an explicit expression for the limit problem. (c) 2000 Académie des sciences/Éditions scientifiques et médicales Elsevier SAS
\end{abstract}

\section{Homogénéisation réitérée d'opérateurs monotones}

Résumé. Nous étudions l'homogénéisation réitérée d'équations non linéaires de la forme - $\operatorname{div}(a(x)$ $\left.\left.\varepsilon, x / \varepsilon^{2}, \mathrm{D} u_{\varepsilon}\right)\right)=f$, où a est une fonction périodique dans les deux premiers arguments et monotone dans le troisième. On trouve que $u_{\varepsilon}$ converge au sens faible dans $\mathrm{W}^{1, p}(\Omega)$ (même à un certain sens multi-échelle), quand $\varepsilon \rightarrow 0$, vers la solution $u_{0}$ d'un problème aux limites. Ensuite, on formule ce problème limite de façon explicite. (C) 2000 Académie des sciences/Éditions scientifiques et médicales Elsevier SAS

\section{Version française abrégée}

La notion d'homogénéisation réitérée a été introduite dans [3], où un résultat pour opérateurs linéaires, connu par la suite sous le nom du théorème d'homogénéisation réitérée, est démontré. Le cas non linéaire correspondant a été étudié, en utilisant la notion de $\Gamma$-convergence, pour des problèmes convexes dans [4] et [6]. Ces résultats ont récemment été utilisés pour la conception de matériaux non linéaires possédant des propriétés d'une efficacité étonnante (voir e.g. [4,6,8] et les références de ces travaux).

Dans cette Note nous étudions l'homogénéisation réitérée pour les opérateurs monotones à l'aide de deux méthodes différentes. La démonstration du théorème 1 a pour base «la méthode d'énergie », et celle du théorème 2 utilise la convergence multi-échelle. Nous examinons les cas d'opérateurs monotones et nous

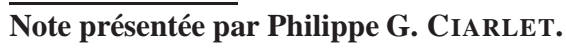

S0764-4442(00)00242-1/FLA

C 2000 Académie des sciences/Éditions scientifiques et médicales Elsevier SAS. Tous droits réservés. 


\section{J.-L. Lions et al.}

considérons la classe d'équations aux dérivées partielles de la forme :

$$
\left\{\begin{array}{l}
-\operatorname{div}\left(a_{\varepsilon}\left(x, \mathrm{D} u_{\varepsilon}\right)\right)=f \quad \operatorname{sur} \Omega \\
u_{\varepsilon} \in \mathrm{W}_{0}^{1, p}(\Omega)
\end{array}\right.
$$

où l'ensemble $\Omega \subset \mathbb{R}^{n}$ est ouvert et borné, $1<p<\infty, 1 / p+1 / q=1$ et où $f \in \mathrm{W}^{-1, q}(\Omega)$. De plus, $a_{\varepsilon}$ est de la forme $a_{\varepsilon}(x, \xi)=a\left(x / \varepsilon, x / \varepsilon^{2}, \xi\right)$, où $a$ est $Y$-périodique et $Z$-périodique dans la première et la seconde variable respectivement. La fonction $a$ est continue par morceaux dans la première variable, c'est-à-dire

$$
a(y, z, \xi)=\sum_{i=1}^{N} \chi_{\Omega_{i}}(y) a_{i}(y, z, \xi)
$$

où $a_{i}$ satisfait

$$
\left|a_{i}\left(y_{1}, z, \xi\right)-a_{i}\left(y_{2}, z, \xi\right)\right|^{q} \leqslant \omega\left(\left|y_{1}-y_{2}\right|\right)\left(1+|\xi|^{p}\right) .
$$

La fonction $\omega: \mathbb{R} \rightarrow \mathbb{R}$ est continue, croissante et $\omega(0)=0$. Dans le troisième argument $a$ satisfait à des conditions appropriées de monotonicité et de continuité.

Nous étudions le comportement asymptotique des solutions $u_{\varepsilon}$ de (1) quand $\varepsilon \rightarrow 0$ et nous démontrons que $u_{\varepsilon}$ converge au sens faible dans $\mathrm{W}_{0}^{1, p}(\Omega)$ (et même à un sens multi-échelle) vers la solution $u_{0}$ d'un problème homogénéisé :

$$
\left\{\begin{array}{l}
-\operatorname{div}\left(b\left(\mathrm{D} u_{0}\right)\right)=f \quad \text { dans } \Omega \\
u_{0} \in \mathrm{W}_{0}^{1, p}(\Omega)
\end{array}\right.
$$

dont la représentation peut être obtenue à partir de $a$ par une réitération d'une «formule d'homogénéisation ». La conception de la convergence multi-échelle a été utilisée par G. Allaire [1] pour étudier l'homogénéisation des problèmes linéaires où non linéaires qui comprenaient deux échelles. Ensuite, G. Allaire et M. Briane ont utilisé la convergence multi-échelle pour étudier des problèmes linéaires d'homogénéisation avec le nombre d'échelles supérieur à deux (voir [2]).

Nous nous contentons seulement de donner les résultats principaux, qui sont des généralisations du théorème d'homogénéisation réitérée.

THÉORÈME 1. - Soient $\left(u_{\varepsilon}\right)$ les solutions de (1). Alors

$$
\begin{aligned}
u_{\varepsilon} \longrightarrow u_{0} & \text { au sens faible dans } \mathrm{W}_{0}^{1, p}(\Omega), \\
a\left(\frac{x}{\varepsilon}, \frac{x}{\varepsilon^{2}}, \mathrm{D} u_{\varepsilon}\right) \longrightarrow b\left(\mathrm{D} u_{0}\right) & \text { au sens faible dans } \mathrm{L}^{q}\left(\Omega, \mathbb{R}^{n}\right),
\end{aligned}
$$

quand $\varepsilon \rightarrow 0$, où $u_{0}$ est la solution unique de (2). L'opérateur $b: \mathbb{R}^{n} \rightarrow \mathbb{R}^{n}$ est défini dans (3), avec $v^{\xi}$ solution unique du "problème cellule»(4). L'opérateur $b_{1}: Y \times \mathbb{R}^{n} \rightarrow \mathbb{R}^{n}$ est défini dans (5), avec v $v^{\xi, y}$ solution unique $d u$ "problème cellule» (6).

On peut généraliser ce résultat au cas où $a_{\varepsilon}$ a la forme $a_{\varepsilon}(x, \xi)=a\left(x, x / \varepsilon, x / \varepsilon^{2}, \xi\right)$. Dans la suite nous supposons que $a_{\varepsilon}$ possède cette forme.

Nous disons qu'une suite $u_{\varepsilon} \ll 3$-scale »-converge vers $u_{0}(x, y, z) \in \mathrm{L}^{p}(\Omega, Y, Z)$ si

$$
\lim _{\varepsilon \rightarrow \infty} \int_{\Omega} u_{\varepsilon}(x) \varphi\left(x, \frac{x}{\varepsilon}, \frac{x}{\varepsilon^{2}}\right) \mathrm{d} x=\frac{1}{|Y||Z|} \int_{\Omega \times Y \times Z} u_{0}(x, y, z) \varphi(x, y, z) \mathrm{d} x \mathrm{~d} y \mathrm{~d} z,
$$

pour chaque $\varphi \in \mathcal{D}\left(\Omega ; \mathrm{C}_{\text {per }}^{\infty}(Y, Z)\right)$ (i.e. fonctions $\varphi(x, y, z)$ qui sont $\mathrm{C}^{\infty}$ à support compact en $x$ et dont les valeurs sont des fonctions $\mathrm{C}^{\infty}$ périodiques en $y$ et $\left.z\right)$. Cette définition est une variante de celle introduite dans [2] pour le cas $p=2$ (voir aussi [1,5] and [7]). 
THÉORÈME 2.-Soit $u_{\varepsilon}$ une solution de (1). Alors, quand $\varepsilon \rightarrow 0$, $u_{\varepsilon}$ «3-scale»-converge vers $u_{0} \in$ $\mathrm{W}_{0}^{1, p}(\Omega)$ et $\mathrm{D} u_{\varepsilon}$ «3-scale »-converge vers $\mathrm{D} u_{0}+\mathrm{D}_{y} u_{1}+\mathrm{D}_{z} u_{2}$, où $\left\{u_{0}, u_{1}, u_{2}\right\}$ satisfait

$$
\frac{1}{|Y||Z|} \int_{\Omega \times Y \times Z} a\left(x, y, z, \mathrm{D} u_{0}+\mathrm{D}_{y} u_{1}+\mathrm{D}_{z} u_{2}\right)\left(\mathrm{D} v_{0}+\mathrm{D}_{y} v_{1}+\mathrm{D}_{z} v_{2}\right) \mathrm{d} x \mathrm{~d} y \mathrm{~d} z=\int_{\Omega} f v_{0} \mathrm{~d} x,
$$

pour chaque $v_{0} \in \mathrm{W}_{0}^{1, p}(\Omega), v_{1} \in \mathrm{L}^{p}\left(\Omega ; \mathrm{W}_{\text {per }}^{1, p}(Y)\right), v_{2} \in \mathrm{L}^{p}\left(\Omega ; \mathrm{W}_{\text {per }}^{1, p}(Y \times Z)\right)$.

Remarque 1. - Les théorèmes donnés ci-dessus peuvent facilement être généralisés au cas où $a_{\varepsilon}$ est de la forme $a_{\varepsilon}(x, \xi)=a\left(x, x / \varepsilon, \ldots, x / \varepsilon^{m}, \xi\right)$.

\section{Introduction}

The concept of reiterated homogenization was introduced in [3], where a result for linear operators was stated which later has been known as the iterated homogenization theorem. The corresponding nonlinear case was studied in the notion of $\Gamma$-convergence in [4] and [6] for convex problems. These results have recently been used to construct nonlinear materials with surprisingly effective behavior (see, e.g., $[4,6]$ and $[8]$ and the references given there).

In this Note we study reiterated homogenization of monotone operators by two different approaches. The proof of Theorem 1 is based on the so-called energy method and in the proof of Theorem 2 we use multiscale convergence. We consider the class of partial differential equations of the form:

$$
\left\{\begin{array}{l}
-\operatorname{div}\left(a_{\varepsilon}\left(x, \mathrm{D} u_{\varepsilon}\right)\right)=f \quad \text { on } \Omega \\
u_{\varepsilon} \in \mathrm{W}_{0}^{1, p}(\Omega)
\end{array}\right.
$$

where $\Omega$ is an open bounded subset of $\mathbb{R}^{n}, 1<p<\infty, 1 / p+1 / q=1$ and $f \in \mathrm{W}^{-1, q}(\Omega)$. Moreover, $a_{\varepsilon}$ is of the form $a_{\varepsilon}(x, \xi)=a\left(x / \varepsilon, x / \varepsilon^{2}, \xi\right)$. Here $a$ is $Y$-periodic and $Z$-periodic in the first and second variable, respectively. Moreover, $a$ is piecewise continuous in the first variable, i.e.,

$$
a(y, z, \xi)=\sum_{i=1}^{N} \chi_{\Omega_{i}}(y) a_{i}(y, z, \xi)
$$

where $a_{i}$ satisfies

$$
\left|a_{i}\left(y_{1}, z, \xi\right)-a_{i}\left(y_{2}, z, \xi\right)\right|^{q} \leqslant \omega\left(\left|y_{1}-y_{2}\right|\right)\left(1+|\xi|^{p}\right),
$$

and $\omega: \mathbb{R} \rightarrow \mathbb{R}$ is continuous, increasing and $\omega(0)=0$. In the third variable $a$ satisfies suitable monotonicity and continuity conditions.

We study the asymptotic behavior of the solutions $u_{\varepsilon}$ of (1) as $\varepsilon \rightarrow 0$ and prove that $u_{\varepsilon}$ converges weakly in $\mathrm{W}_{0}^{1, p}(\Omega)$ (and even in some multiscale sense) to the solution $u_{0}$ of a homogenized problem:

$$
\left\{\begin{array}{l}
-\operatorname{div}\left(b\left(\mathrm{D} u_{0}\right)=f \quad \text { on } \Omega\right. \\
u_{0} \in \mathrm{W}_{0}^{1, p}(\Omega)
\end{array}\right.
$$

whose representation can be obtained from $a$ by reiteration of a "homogenization formula". The concept of multiscale convergence was used by G. Allaire in [1] to study homogenization of both linear and nonlinear problems involving two scales. Later on G. Allaire and M. Briane used multiscale convergence to study linear homogenization problems with more than two scales (see [2]). 


\section{J.-L. Lions et al.}

\section{Homogenization results}

Below we state the main results, which are generalizations of the classical iterated homogenization theorem.

THEOREM 1.- Let $\left(u_{\varepsilon}\right)$ be the solutions of (1). Then

$$
\begin{array}{cc}
u_{\varepsilon} \longrightarrow u_{0} & \text { weakly in } \mathrm{W}_{0}^{1, p}(\Omega), \\
a\left(\frac{x}{\varepsilon}, \frac{x}{\varepsilon^{2}}, \mathrm{D} u_{\varepsilon}\right) \longrightarrow b\left(\mathrm{D} u_{0}\right) & \text { weakly in } \mathrm{L}^{q}\left(\Omega, \mathbb{R}^{n}\right),
\end{array}
$$

as $\varepsilon \rightarrow 0$, where $u_{0}$ is the unique solution of:

$$
\left\{\begin{array}{l}
\int_{\Omega}\left(b\left(\mathrm{D} u_{0}\right), \mathrm{D} \phi\right) \mathrm{d} x=\langle f, \phi\rangle \quad \text { for every } \phi \in \mathrm{W}_{0}^{1, p}(\Omega), \\
u_{0} \in \mathrm{W}_{0}^{1, p}(\Omega)
\end{array}\right.
$$

The operator $b: \mathbb{R}^{n} \rightarrow \mathbb{R}^{n}$ is defined as:

$$
b(\xi)=\frac{1}{|Y|} \int_{Y} b_{1}\left(y, \xi+\mathrm{D} v^{\xi}(y)\right) \mathrm{d} y
$$

where $v^{\xi}$ is the unique solution of the cell-problem:

$$
\left\{\begin{array}{l}
\int_{Y}\left(b_{1}\left(y, \xi+\mathrm{D} v^{\xi}(y)\right), \mathrm{D} \phi\right) \mathrm{d} y=0 \quad \text { for every } \phi \in \mathrm{W}_{\mathrm{per}}^{1, p}(Y), \\
v^{\xi} \in \mathrm{W}_{\text {per }}^{1, p}(Y) .
\end{array}\right.
$$

The operator $b_{1}: Y \times \mathbb{R}^{n} \rightarrow \mathbb{R}^{n}$ is defined as

$$
b_{1}(y, \xi)=\frac{1}{|Z|} \int_{Z} a\left(y, z, \xi+\mathrm{D} v^{\xi, y}(z)\right) \mathrm{d} z
$$

where $v^{\xi, y}$ is the unique solution of the cell-problem:

$$
\left\{\begin{array}{l}
\int_{Z}\left(a\left(y, z, \xi+\mathrm{D} v^{\xi, y}(z)\right), \mathrm{D} \phi\right) \mathrm{d} z=0 \quad \text { for every } \phi \in \mathrm{W}_{\text {per }}^{1, p}(Z) \\
v^{\xi} \in \mathrm{W}_{\text {per }}^{1, p}(Z)
\end{array}\right.
$$

Sketch of the proof. - First we note that $u_{\varepsilon}$ and $a\left(x / \varepsilon, x / \varepsilon^{2}, \mathrm{D} u_{\varepsilon}\right)$ are bounded in $\mathrm{W}_{0}^{1, p}(\Omega)$ and $\mathrm{L}^{q}\left(\Omega, \mathbb{R}^{n}\right)$, respectively. This means that there exists subsequences, still denoted by the subindex $\varepsilon$, such that

$$
\begin{aligned}
u_{\varepsilon} & \longrightarrow u_{*} \quad \text { weakly in } \mathrm{W}_{0}^{1, p}(\Omega), \\
a\left(\frac{x}{\varepsilon}, \frac{x}{\varepsilon^{2}}, \mathrm{D} u_{\varepsilon}\right) & \longrightarrow \eta \quad \text { weakly in } \mathrm{L}^{q}\left(\Omega, \mathbb{R}^{n}\right) .
\end{aligned}
$$

In the limit we get that the following equation is satisfied:

$$
-\operatorname{div} \eta=f \quad \text { on } \Omega .
$$


If we now show that $\eta=b\left(\mathrm{D} u_{*}\right)$ then it follows by the uniqueness of the homogenized equation (2) that $u_{*}=u_{0}$. To this end let $u_{\varepsilon}^{\xi}$ be defined as the solution of the auxiliary problem:

$$
\left\{\begin{array}{l}
\int_{Y}\left(a\left(x, \frac{x}{\varepsilon}, \xi+\mathrm{D} u_{\varepsilon}^{\xi}\right), \mathrm{D} \phi\right) \mathrm{d} x=0 \quad \text { for every } \phi \in \mathrm{W}_{\text {per }}^{1, p}(Y), \\
u_{\varepsilon}^{\xi} \in \mathrm{W}_{\text {per }}^{1, p}(Y)
\end{array}\right.
$$

Then it is possible to show that

$$
\begin{array}{cr}
u_{\varepsilon}^{\xi} \longrightarrow u_{0}^{\xi} & \text { weakly in } \mathrm{W}_{\text {per }}^{1, p}(Y), \\
a\left(x, \frac{x}{\varepsilon}, \mathrm{D} u_{\varepsilon}^{\xi}\right) \longrightarrow b_{1}\left(x, \xi+\mathrm{D} u_{0}^{\xi}\right) & \text { weakly in } \mathrm{L}^{q}\left(Y, \mathbb{R}^{n}\right),
\end{array}
$$

as $\varepsilon \rightarrow 0$, where $u_{0}^{\xi}$ is the unique solution of

$$
\left\{\begin{array}{l}
\int_{Y}\left(b_{1}\left(x, \xi+\mathrm{D} u_{0}^{\xi}\right), \mathrm{D} \phi\right) \mathrm{d} x=0 \quad \text { for every } \phi \in \mathrm{W}_{\text {per }}^{1, p}(Y), \\
u_{0}^{\xi} \in \mathrm{W}_{\text {per }}^{1, p}(Y)
\end{array}\right.
$$

Let us now define the function

$$
w_{\varepsilon}^{\xi}(x)=(\xi, x)+\varepsilon u_{\varepsilon}^{\xi}\left(\frac{x}{\varepsilon}\right) .
$$

By the monotonicity of $a$ we have, for a fix $\xi$, that

$$
\int_{\Omega}\left(a\left(\frac{x}{\varepsilon}, \frac{x}{\varepsilon^{2}}, \mathrm{D} u_{\varepsilon}\right)-a\left(\frac{x}{\varepsilon}, \frac{x}{\varepsilon^{2}}, \mathrm{D} w_{\varepsilon}^{\xi}\right), \mathrm{D} u_{\varepsilon}-\mathrm{D} w_{\varepsilon}^{\xi}\right) \phi \mathrm{d} x \geqslant 0
$$

for every $\phi \in \mathrm{C}_{0}^{\infty}(\Omega), \phi \geqslant 0$. Compensated compactness and periodicity implies that we have in the limit

$$
\int_{\Omega}\left(\eta(x)-b(\xi), \mathrm{D} u_{*}-\xi\right) \phi \mathrm{d} x \geqslant 0,
$$

for every $\phi \in \mathrm{C}_{0}^{\infty}(\Omega), \phi \geqslant 0$. By a density argument we obtain that

$$
\left(\eta(x)-b(\xi), \mathrm{D} u_{*}-\xi\right) \geqslant 0 \quad \text { for a.e. } x \in \Omega \text { and for every } \xi \in \mathbb{R}^{n} .
$$

It is possible to prove that $b$ is maximal monotone. This means that $\eta=b\left(\mathrm{D} u_{*}\right)$ and we are done.

It is possible to extend this result to the case when $a_{\varepsilon}$ is of the form $a_{\varepsilon}(x, \xi)=a\left(x, x / \varepsilon, x / \varepsilon^{2}, \xi\right)$. From now on we assume that $a_{\varepsilon}$ is of this form.

A sequence $u_{\varepsilon}$ is said to 3 -scale converge to $u_{0}(x, y, z) \in \mathrm{L}^{p}(\Omega, Y, Z)$ if

$$
\lim _{\varepsilon \rightarrow \infty} \int_{\Omega} u_{\varepsilon}(x) \varphi\left(x, \frac{x}{\varepsilon}, \frac{x}{\varepsilon^{2}}\right) \mathrm{d} x=\frac{1}{|Y||Z|} \int_{\Omega \times Y \times Z} u_{0}(x, y, z) \varphi(x, y, z) \mathrm{d} x \mathrm{~d} y \mathrm{~d} z,
$$

for all $\varphi \in \mathcal{D}\left(\Omega ; \mathrm{C}_{\text {per }}^{\infty}(Y, Z)\right)$ (i.e., functions $\varphi(x, y, z)$ which are $\mathrm{C}^{\infty}$ with compact support in $x$ with values of functions which are $\mathrm{C}^{\infty}$ and periodic in $y$ and $z$ ). This definition is a variant of the one introduced in [2] for the case $p=2$ (see also [1,5] and [7]). 


\section{J.-L. Lions et al.}

THEOREM 2. - Let $u_{\varepsilon}$ be a solution of (1). Then as $\varepsilon \rightarrow 0$, it holds that $u_{\varepsilon}$ 3-scale converges to $u_{0} \in \mathrm{W}_{0}^{1, p}(\Omega)$ and $\mathrm{D} u_{\varepsilon} 3$-scale converges to $\mathrm{D} u_{0}+\mathrm{D}_{y} u_{1}+\mathrm{D}_{z} u_{2}$, where $\left\{u_{0}, u_{1}, u_{2}\right\}$ is a solution of

$$
\frac{1}{|Y||Z|} \int_{\Omega \times Y \times Z} a\left(x, y, z, \mathrm{D} u_{0}+\mathrm{D}_{y} u_{1}+\mathrm{D}_{z} u_{2}\right)\left(\mathrm{D} v_{0}+\mathrm{D}_{y} v_{1}+\mathrm{D}_{z} v_{2}\right) \mathrm{d} x \mathrm{~d} y \mathrm{~d} z=\int_{\Omega} f v_{0} \mathrm{~d} x,
$$

for all $v_{0} \in \mathrm{W}_{0}^{1, p}(\Omega), v_{1} \in \mathrm{L}^{p}\left(\Omega ; \mathrm{W}_{\text {per }}^{1, p}(Y)\right), v_{2} \in \mathrm{L}^{p}\left(\Omega ; \mathrm{W}_{\mathrm{per}}^{1, p}(Y \times Z)\right)$.

Remark 1. - The theorems above can easily be extended to the case when $a_{\varepsilon}$ is on the form $a_{\varepsilon}(x, \xi)=$ $a\left(x, x / \varepsilon, \ldots, x / \varepsilon^{m}, \xi\right)$.

\section{References}

[1] Allaire G., Homogenization and two-scale convergence, SIAM J. Math. Anal. 23 (6) (1992) 1482-1518.

[2] Allaire G., Briane M., Multiscale convergence and reiterated homogenization, Proc. Roy. Soc. Edinburgh Sect. A 126 (1996) 297-342.

[3] Bensoussan A., Lions J.-L., Papanicolaou G.C., Asymptotic Analysis for Periodic Structures, North-Holland, Amsterdam, 1978.

[4] Braides A., Lukkassen D., Reiterated homogenization of integral functionals, Math. Mod. Meth. Appl. Sci. 10 (1) (2000) 1-25.

[5] Cioranescu D., Donato P., Introduction to Homogenization, Oxford University Press, Oxford, 1999.

[6] Lukkassen D., Formulae and bounds connected to optimal design and homogenization of partial differential operators and integral functionals, Ph.D. thesis, Dept. of Math., Tromsö University, Norway, 1996.

[7] Nguetseng G., A general convergence result for a functional related to the theory of homogenization, SIAM J. Math. Anal. 20 (3) (1989) 608-623.

[8] Wall P., Homogenization of some partial differential operators and integral functionals, Ph.D. thesis, Dept. of Math., Luleå University of Technology, Luleå, Sweden, 1998. 